\title{
SEPTOCYLINDRINS A AND B: PEPTAIBOLS PRODUCED BY THE TERRESTRIAL FUNGUS SEPTOCYLINDRIUM SP. LL-Z1518 ${ }^{\perp}$
}

Mia Y. Summers, * Fangming Kong, Xidong Feng, Marshall M. Siegel, Jeffrey E. Janso, Edmund I. Graziani, and Guy T. Carter

Department of Chemical and Screening Sciences, Wyeth Research 401 N. Middletown Rd., Pearl River, New York 10965

${ }^{\perp}$ Dedicated to the late Dr. Kenneth L. Rinehart, of the University of Illinois at UrbanaChampaign, for his pioneering work on bioactive natural products.

* author to whom correspondence should be addressed. Tel: 845-602-5493. Fax: 845602-5687. E-mail: summerm@wyeth.com. 
S1. ${ }^{1} \mathrm{H}$ NMR spectrum of Compound 1 (400 MHz, DMSO- $d_{6}$ )

S2. ${ }^{13} \mathrm{C}$ NMR spectrum of Compound $1\left(100 \mathrm{MHz}, \mathrm{DMSO}-d_{6}\right)$

S3. TOCSY spectrum of Compound 1 in DMSO- $d_{6}$

S4. NOESY spectrum of Compound 1 in DMSO- $d_{6}$

S5. HMBC spectrum of Compound 1 in DMSO- $d_{6}$

S6. Multiplicity edited HSQC spectrum of Compound 1 in DMSO- $d_{6}$

S7. ${ }^{15} \mathrm{~N}$ multiplicity edited HSQC spectrum of Compound 1 in DMSO- $d_{6}$

S8. IR spectrum of Compound 1

S9. IR spectrum of Compound 2

S10. FTMS/MS spectrum of Compound 1 parent ion m/z 2007.16647

S11. FTMS/MS spectrum of Compound 1 daughter ion m/z 1189.69540

S12. FTMS/MS spectrum of Compound 1 daughter ion $\mathrm{m} / \mathrm{z} 818.47735$

S13. FTMS/MS spectrum of Compound 2 parent ion m/z 2006.18009

S14. FTMS/MS spectrum of Compound 2 daughter ion m/z 817.49319 


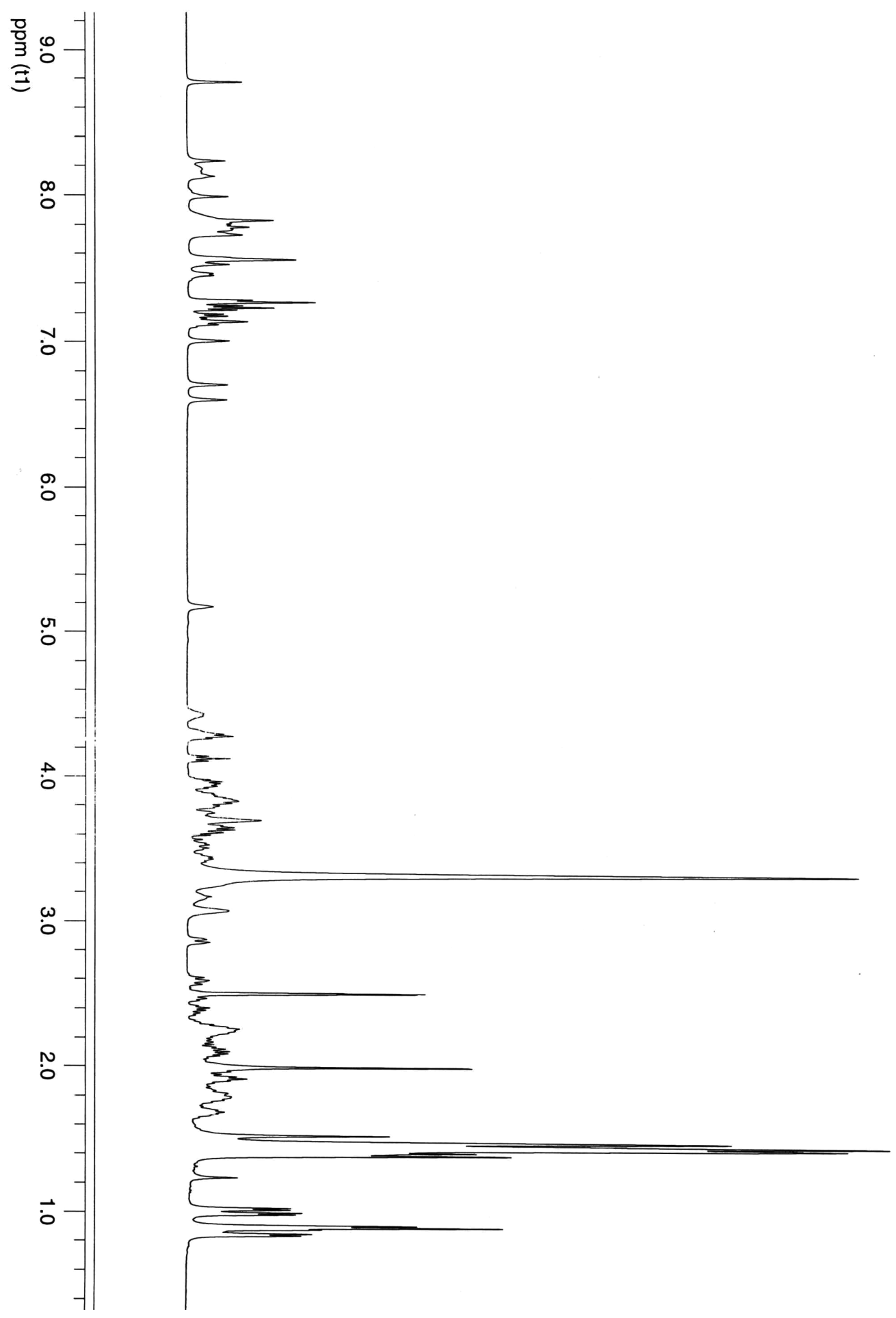

S1. ${ }^{1} \mathrm{H}$ NMR spectrum of Compound 1 (400 MHz, DMSO- $\left.d_{6}\right)$ 


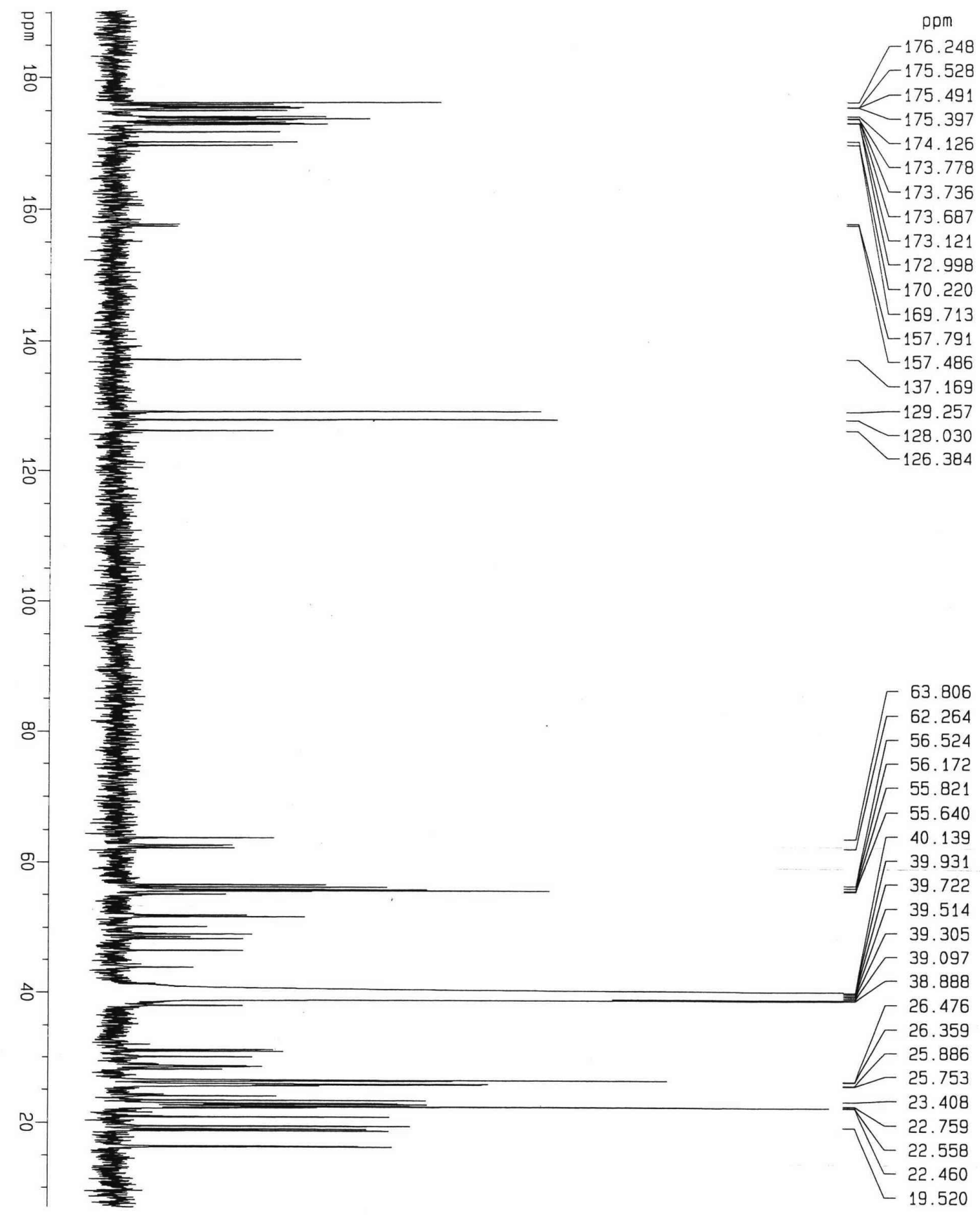

S2. ${ }^{13} \mathrm{C}$ NMR spectrum of Compound 1 (100 MHz, DMSO- $\left.d_{6}\right)$ 


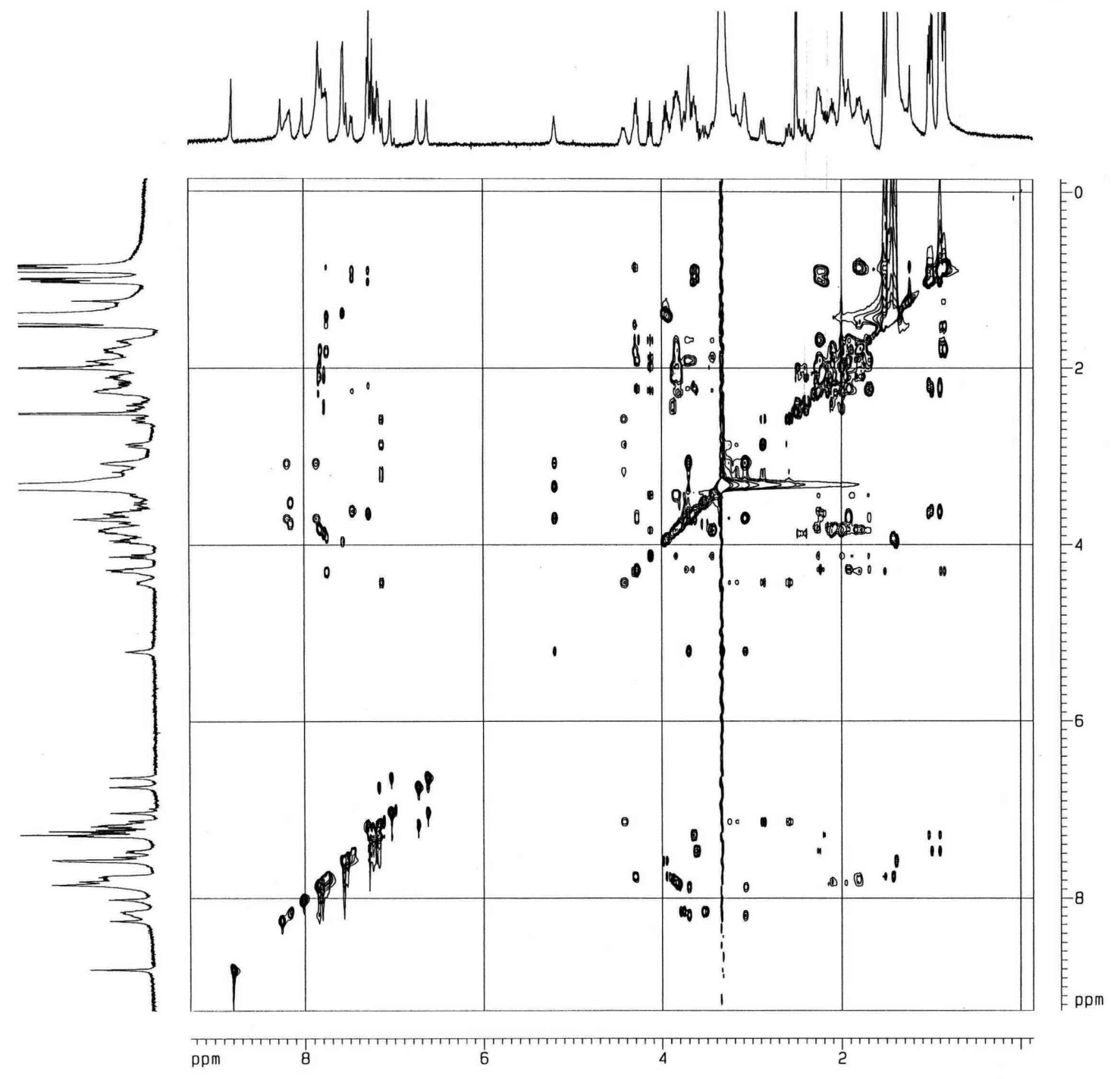

S3. TOCSY spectrum of Compound 1 in DMSO- $d_{6}$ 


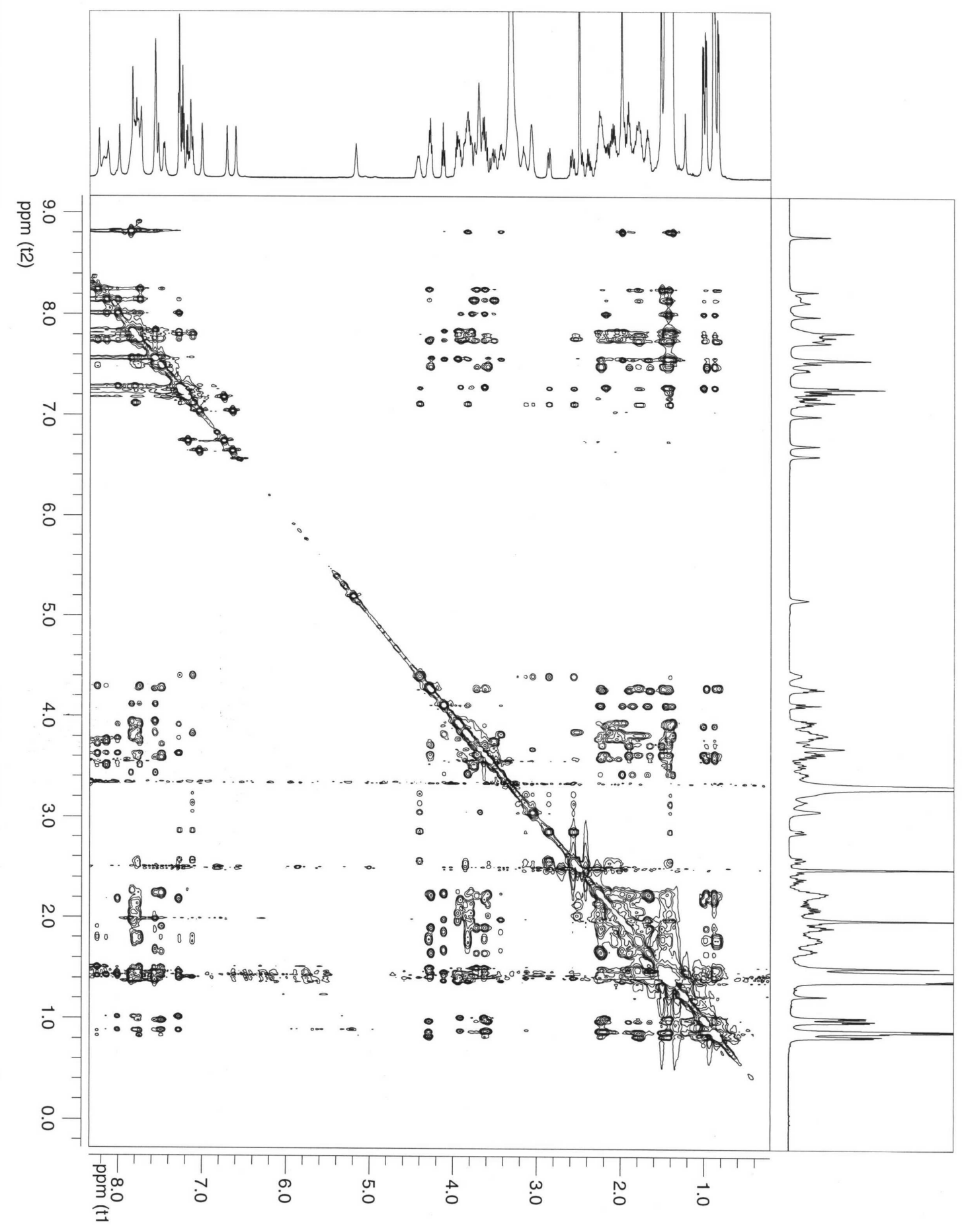

S4. NOESY spectrum of Compound 1 in DMSO- $d_{6}$ 


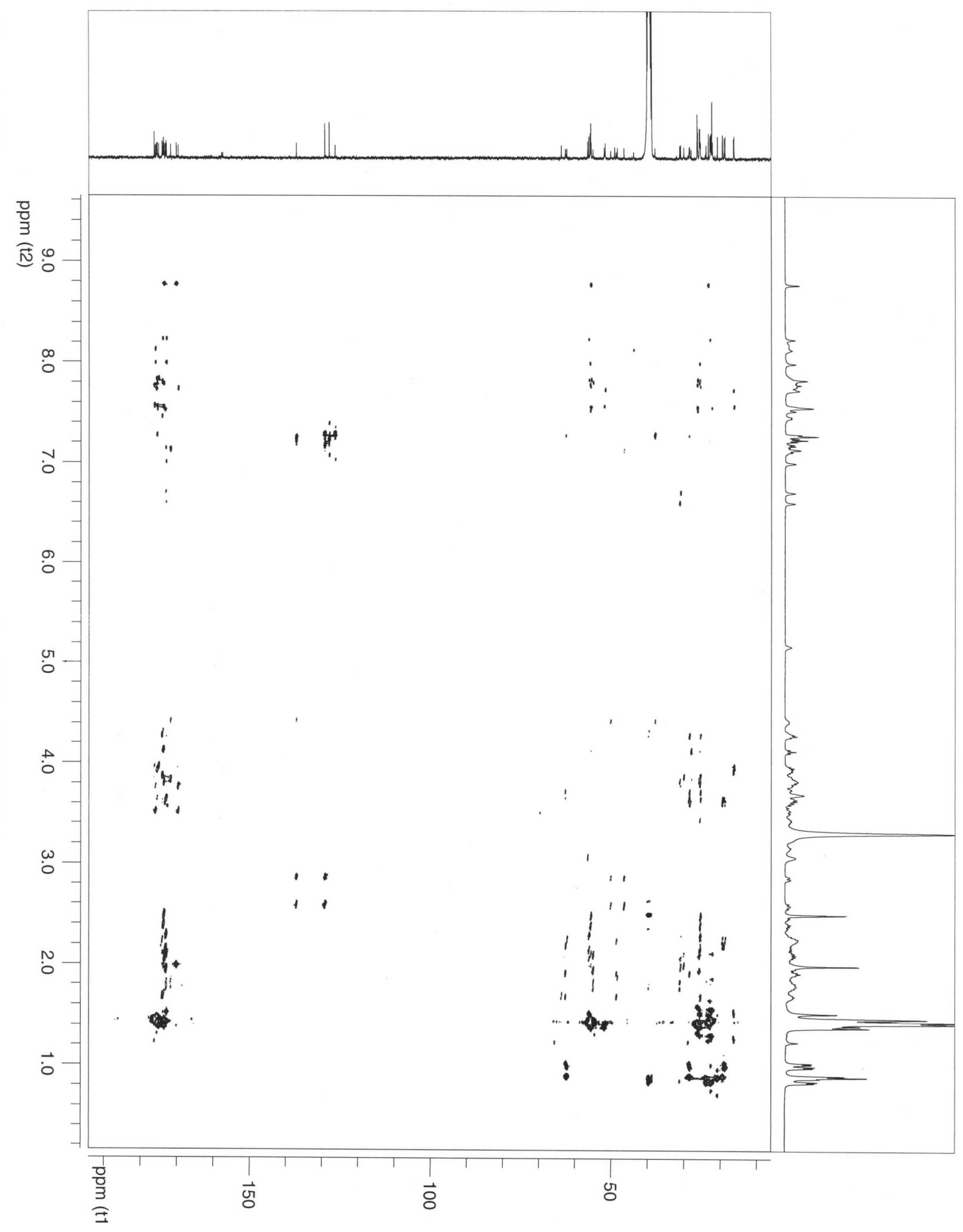

S5. HMBC spectrum of Compound 1 in DMSO- $d_{6}$ 


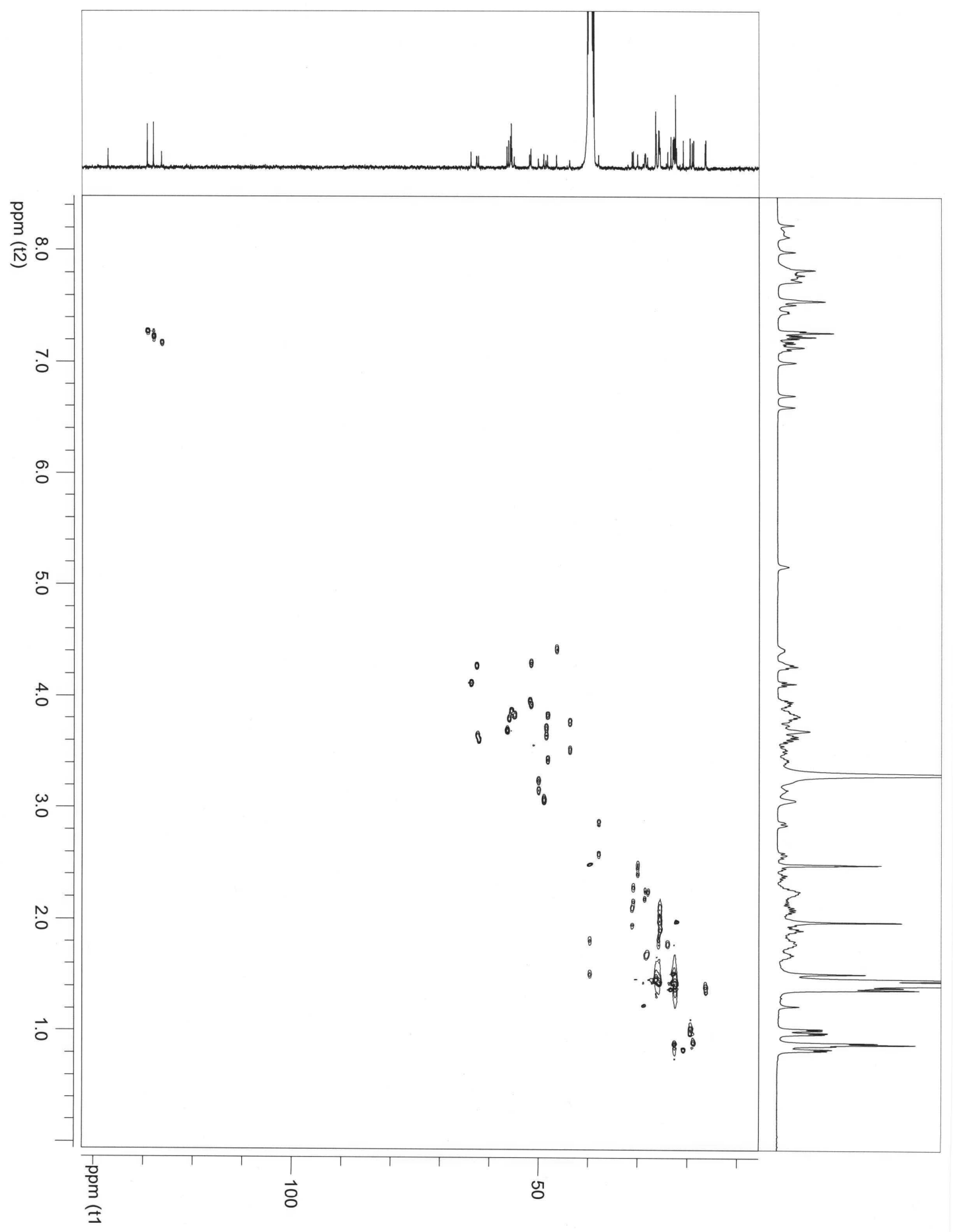

S6. Multiplicity edited HSQC spectrum of Compound 1 in DMSO- $d_{6}$ 


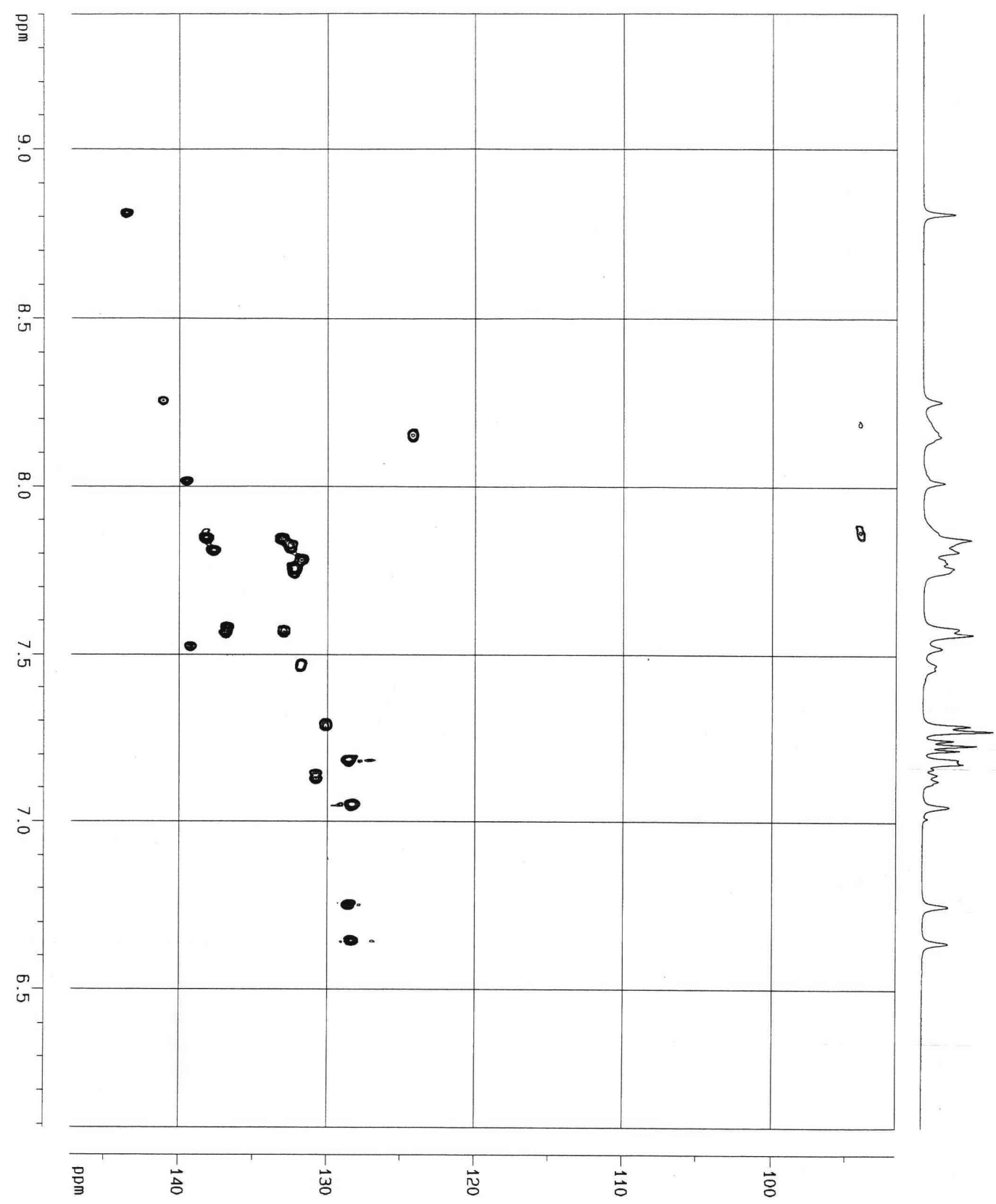

S7. ${ }^{15} \mathrm{~N}$ multiplicity edited HSQC spectrum of Compound 1 in DMSO- $d_{6}$ 


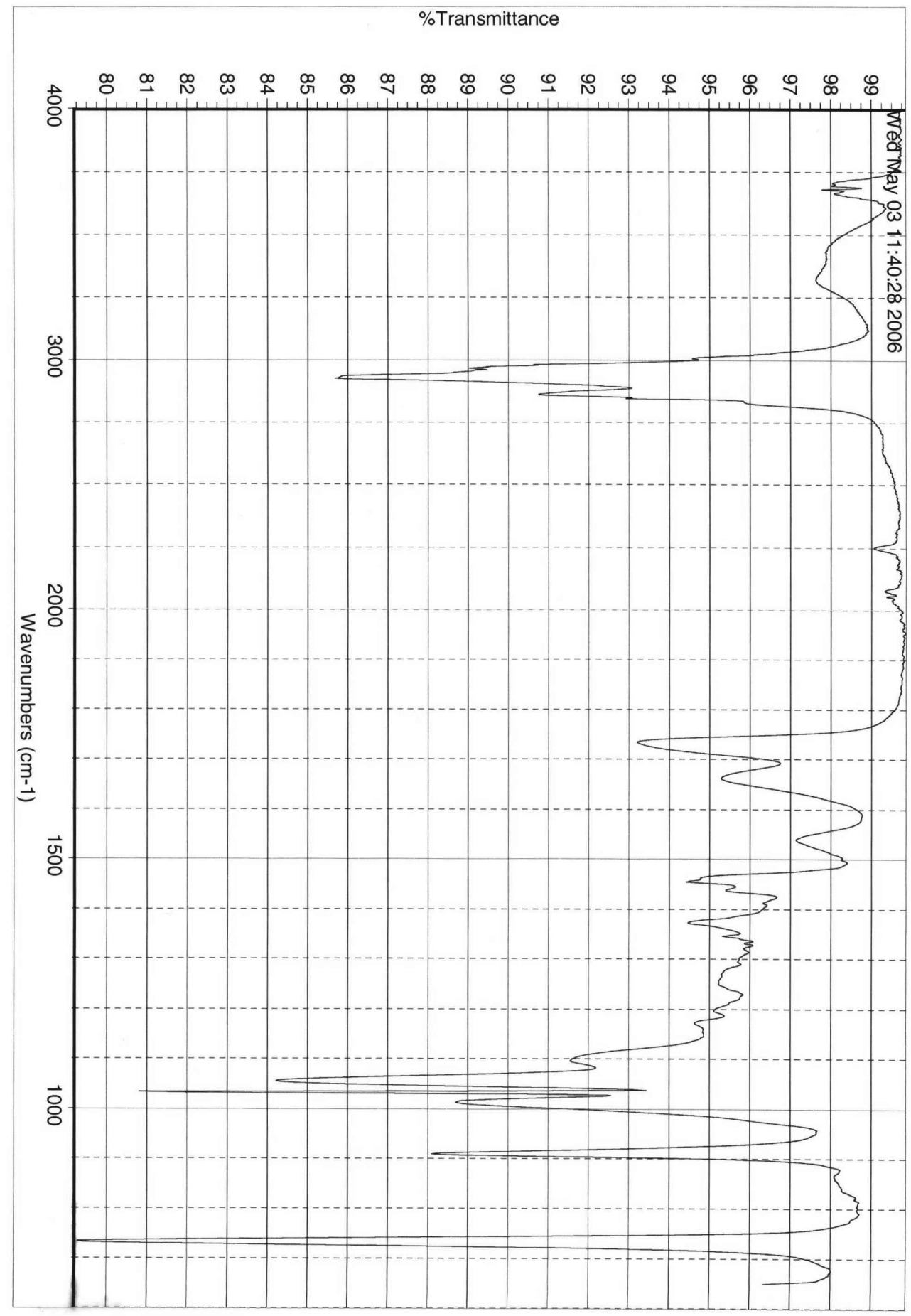

S8. IR spectrum of Compound 1 


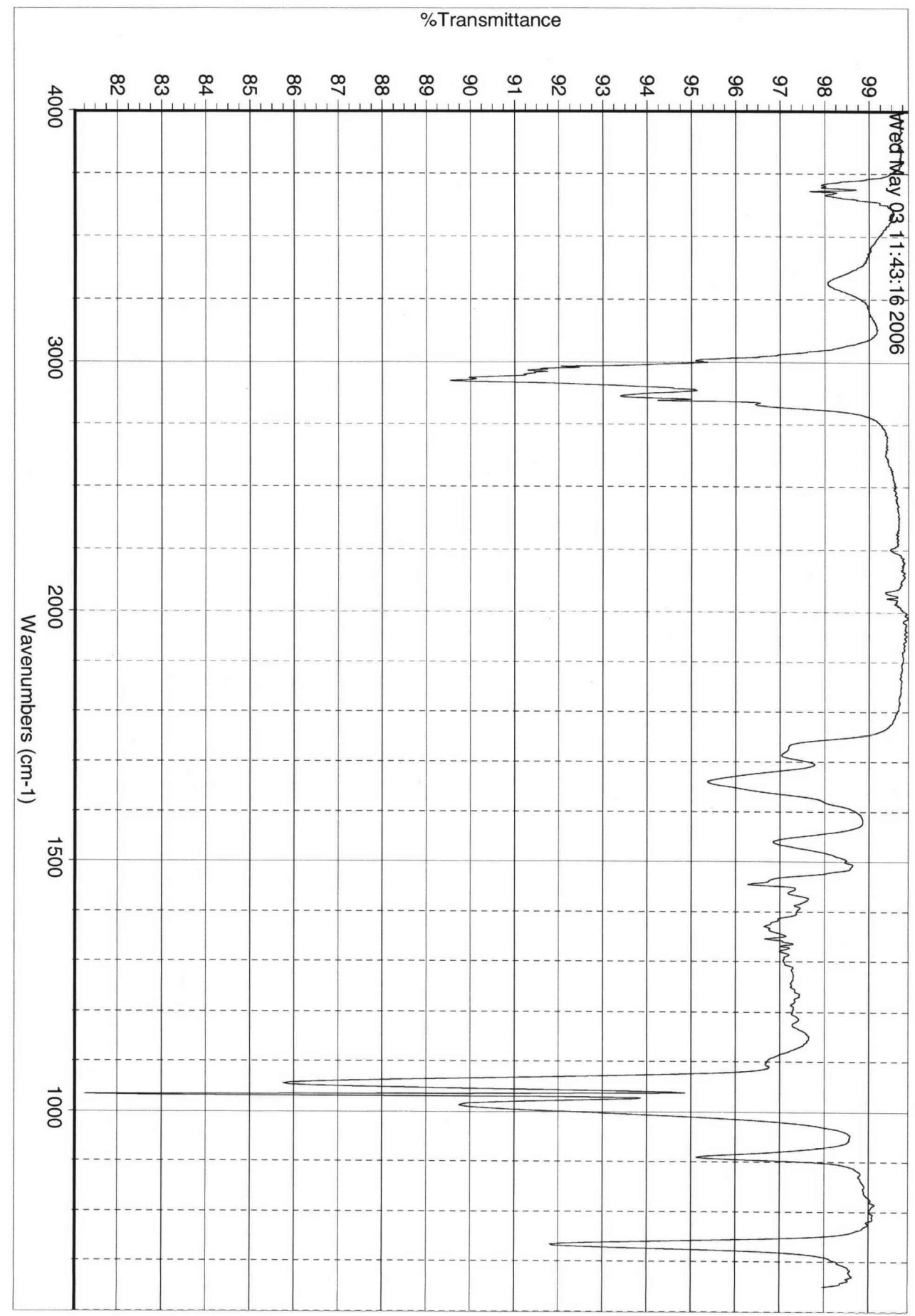

S9. IR spectrum of Compound 2 


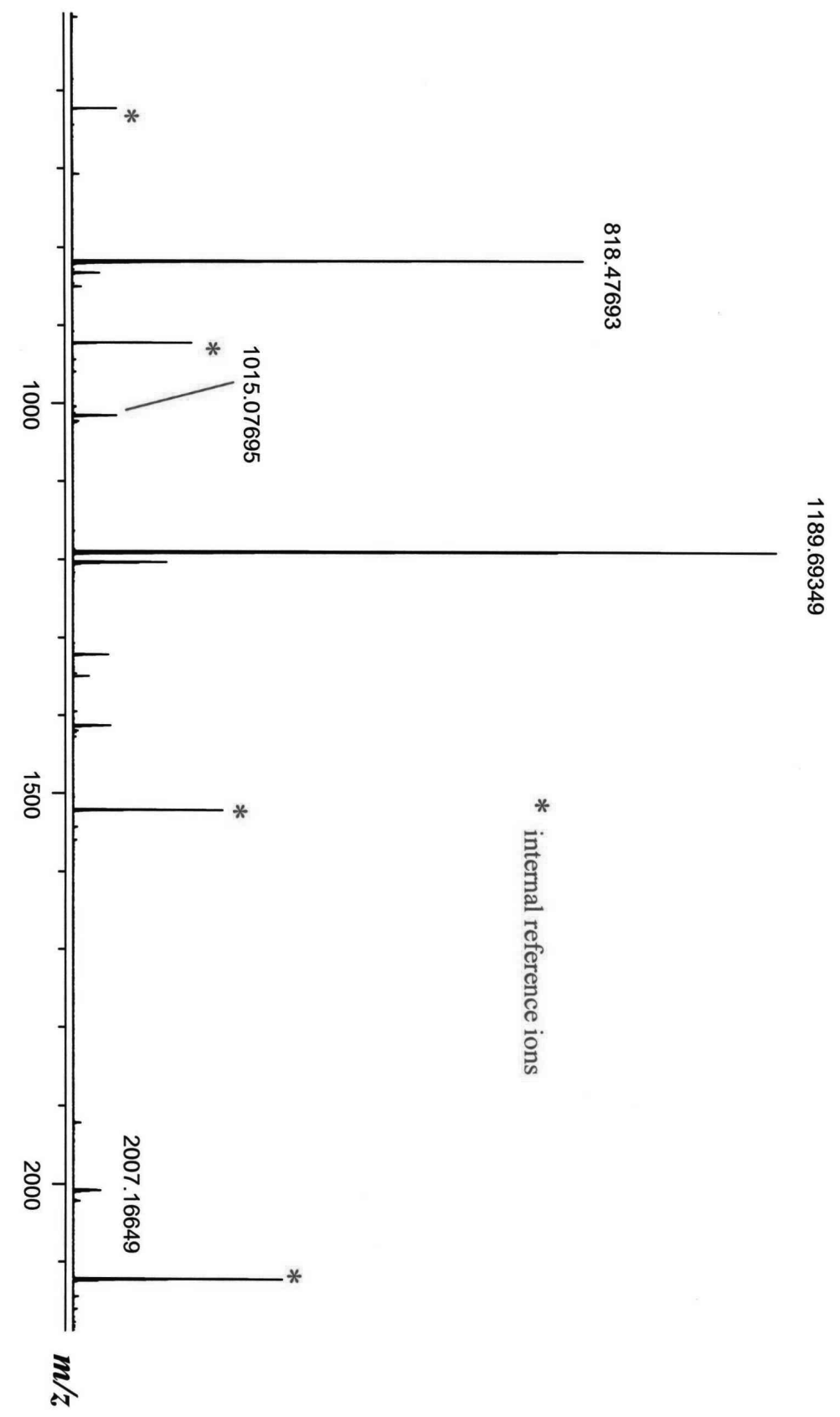

S10. FTMS/MS spectrum of Compound 1 parent ion m/z 2007.16647 


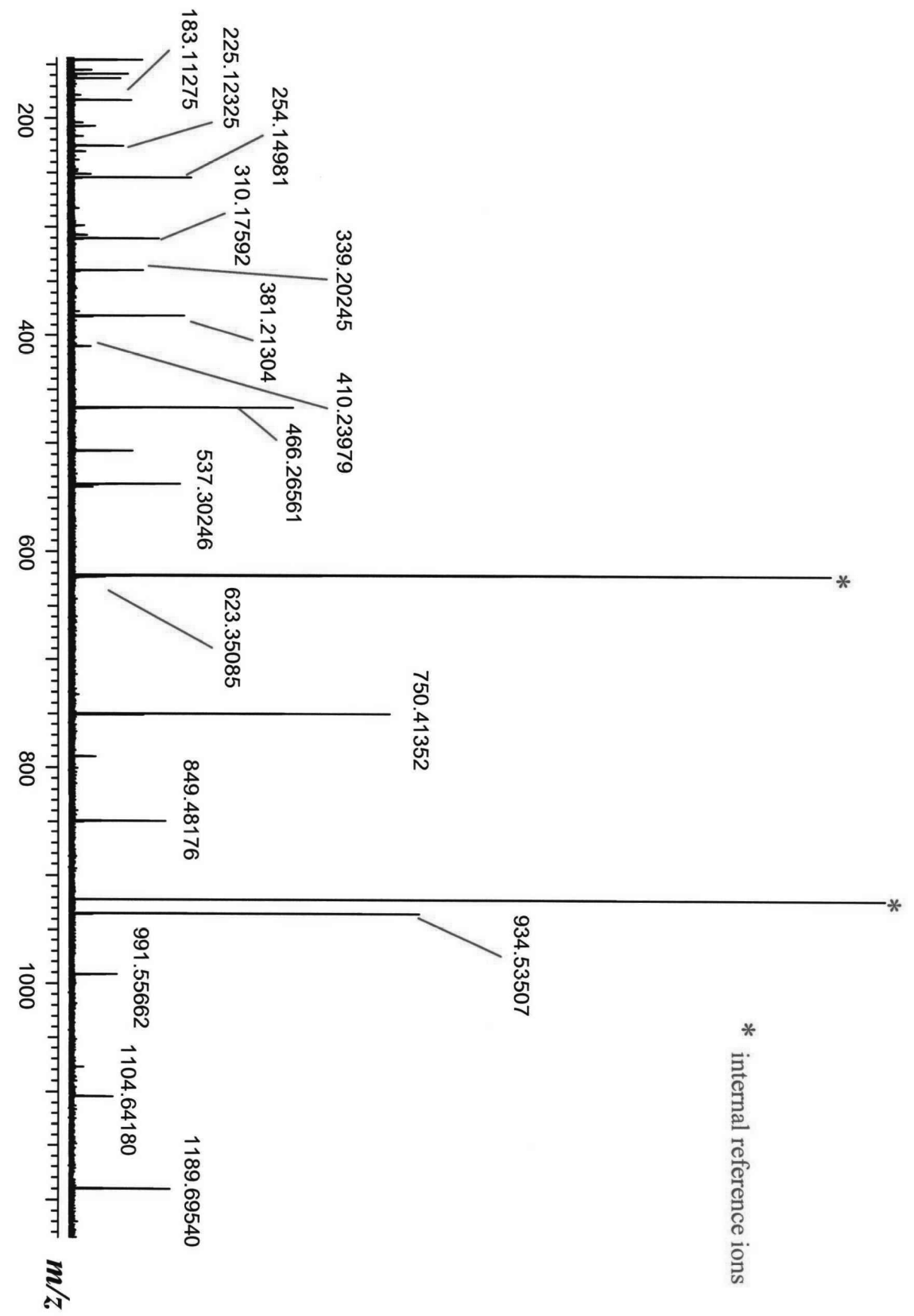

S11. FTMS/MS spectrum of Compound 1 daughter ion m/z 1189.69540 


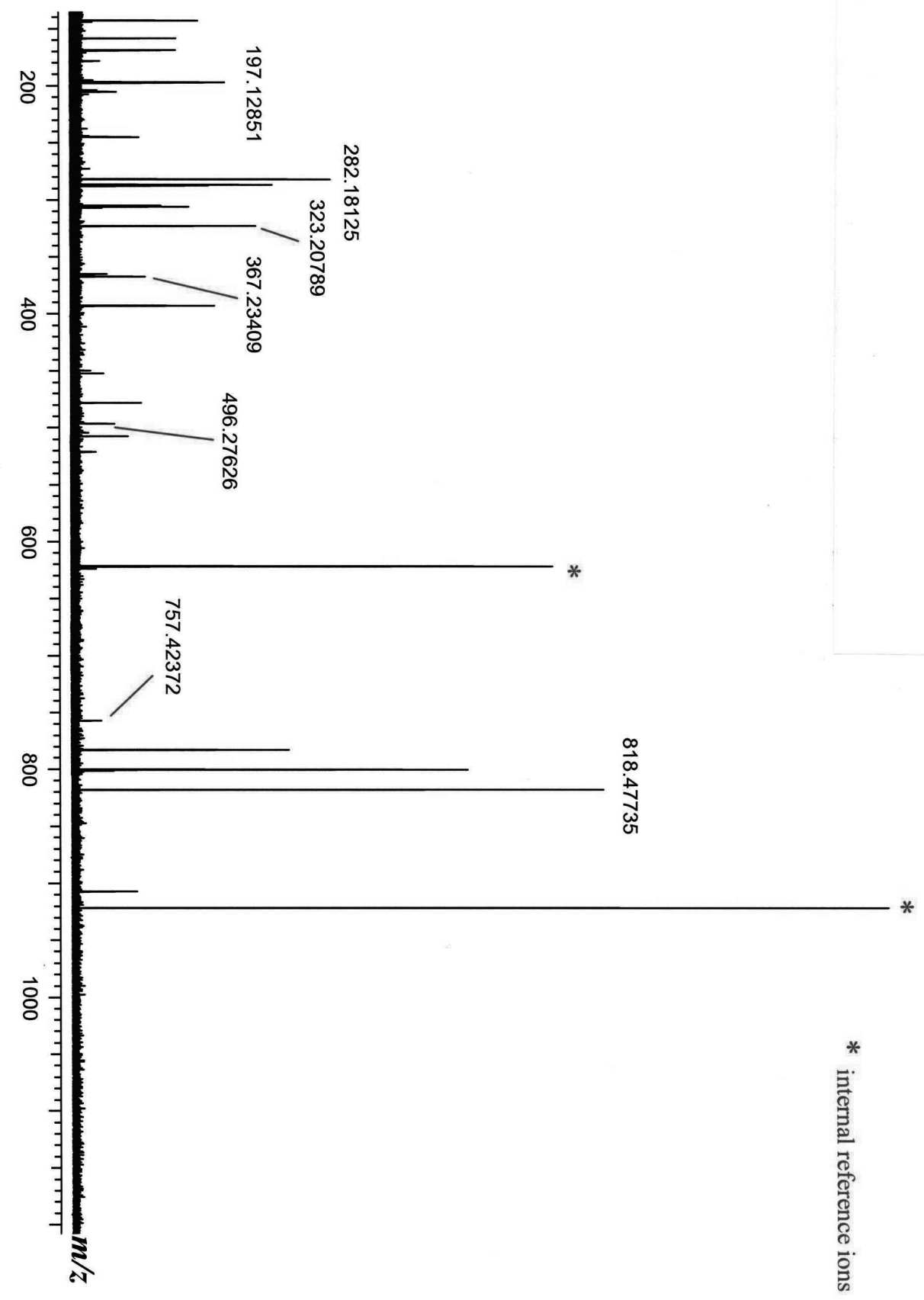

S12. FTMS/MS spectrum of Compound 1 daughter ion m/z 818.47735 


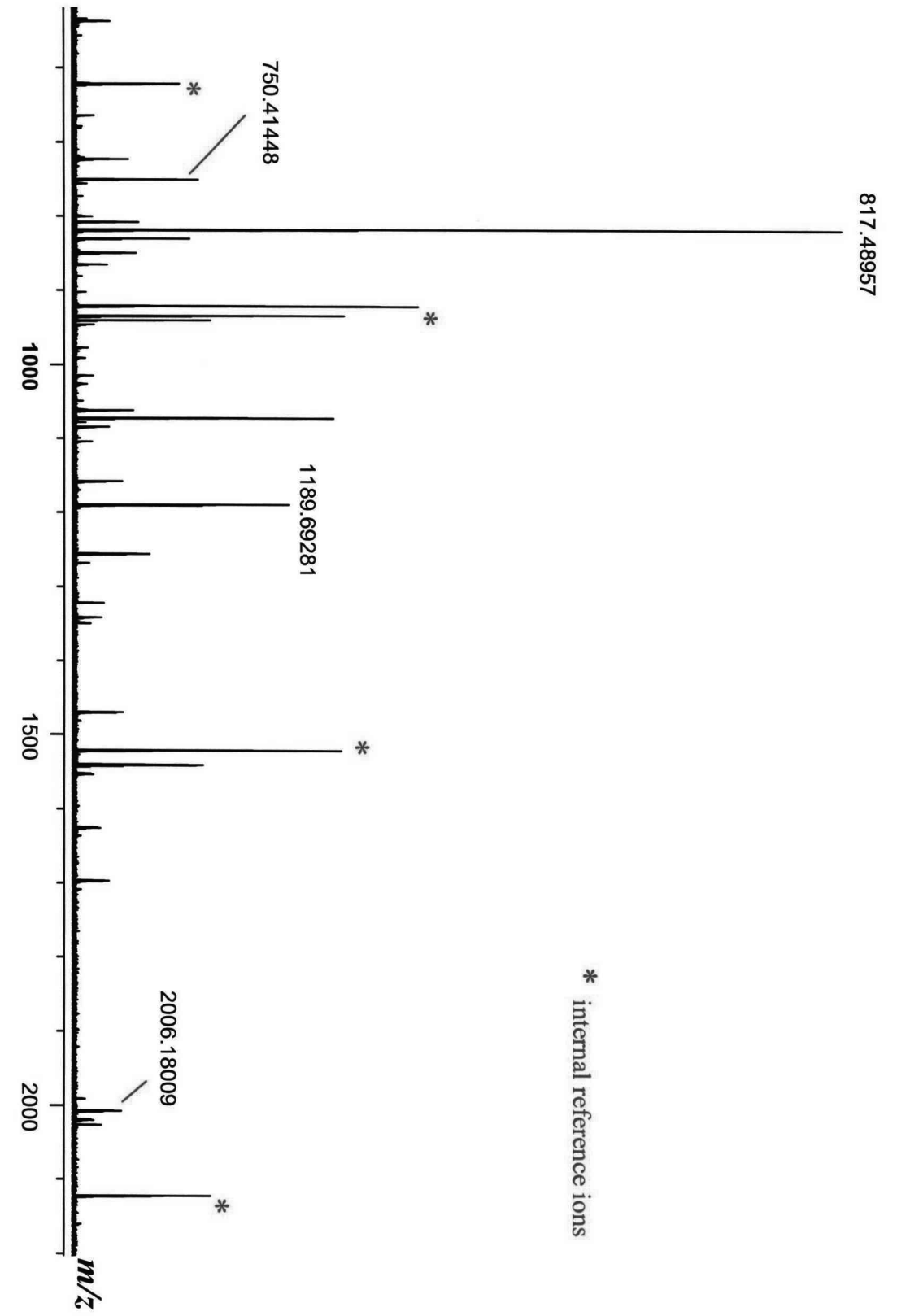

S13. FTMS/MS spectrum of Compound 2 parent ion m/z 2006.18009 


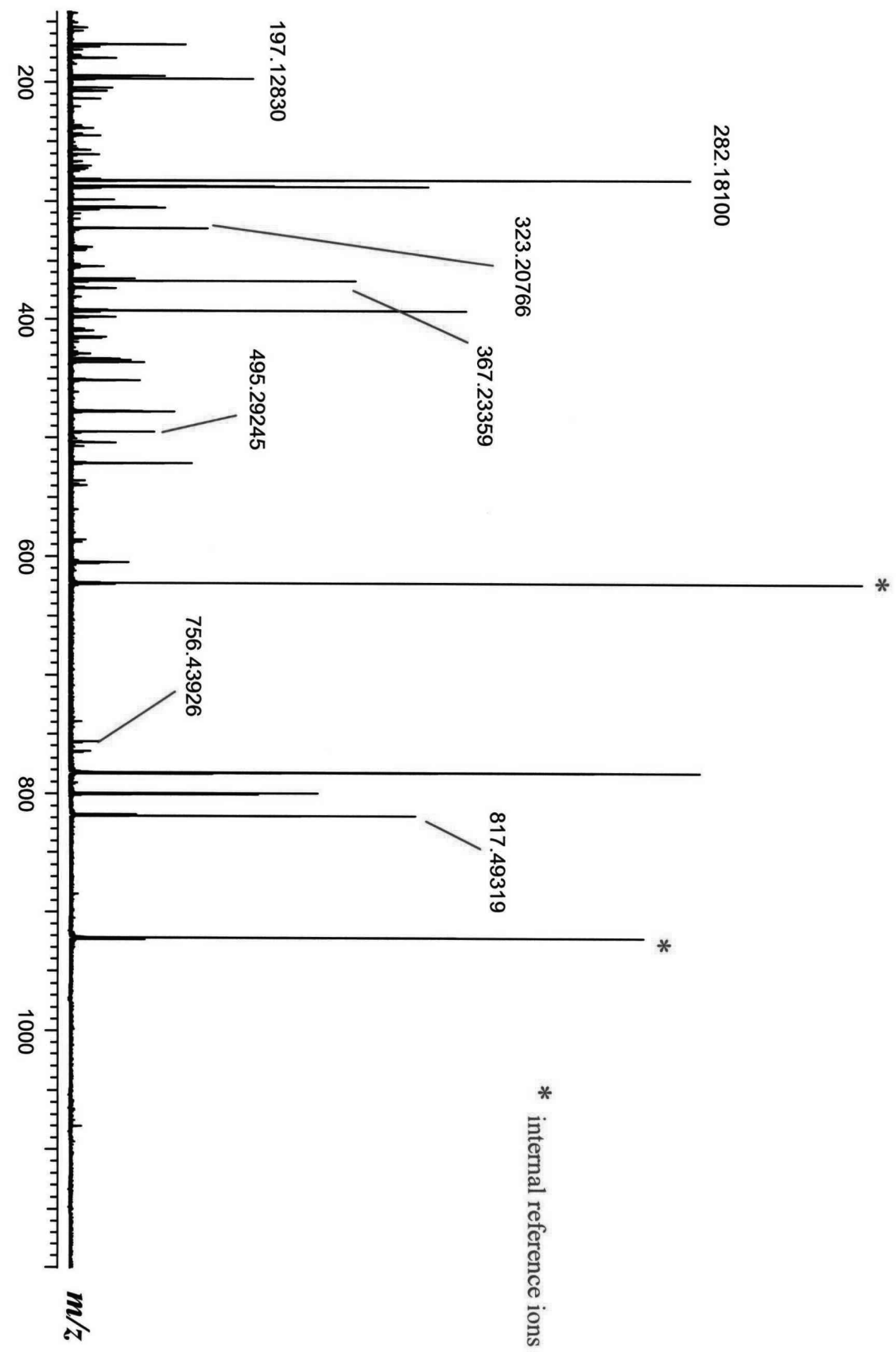

S14. FTMS/MS spectrum of Compound 2 daughter ion m/z 817.49319 